

\section{El carnaval en Alhama de Granada}

\author{
María del Rosario Ortiz Amores, \\ antropóloga social y cultural, \\ integrante del equipo de investigación \\ del Atlas del Patrimonio Inmaterial de \\ Andalucia
}

No puede existir duda cuando se afirma que la gran fiesta de invierno de la localidad de Alhama de Granada, municipio situado en la comarca del Poniente Granadino, es el carnaval.

Dentro del calendario festivo de los alhameños, en el mes de febrero, con temperaturas generalmente bajas propias del frío invierno, el municipio alcanza durante la celebración del carnaval los momentos ritualizados de mayor intensidad y brillantez. Durante las fechas de celebración, que han permanecido inalterables en los últimos tiempos, tres dias antes del miércoles de ceniza y el domingo siguiente a éste, el "Domingo de Piñata", se revisan con espíritu crítico y burlesco los acontecimientos o sucesos más relevantes acaecidos durante el año.

La primera referencia escrita que existe sobre la celebración del Carnaval de Alhama se encuentra en el Archivo del Ayuntamiento (libro $X$ de las Actas Capitulares, folio $120 \mathrm{v}$ y $121 \mathrm{~V}$, del Archivo Histórico de Alhama, con fecha 5 de noviembre de 1571). Así aparece recogido en el libro Memoria Viva del Carnaval de Alhama de Granada, (1917-1979), donde se extrae del último trabajo de Salvador Raya (2003), titulado Alhama. La huella de una ciudad en sus documentos 1568-1637. En él se detalla cómo en el cabildo se recibió una carta en la que se comunicaba la victoria de Lepanto, hecho que se decidió festejar en la población con diversos actos, entre ellos "que se salga disfrazado libremente durante todo el dia hasta el domingo por la noche, sin llevar armas ni máscaras". Posteriormente a estos hechos, se encuentran referencias similares en el siglo XIX, con motivo de la boda de la Reina María Cristina que se celebró con una fiesta de disfraces.

El Carnaval en Alhama se paraliza, como en otras localidades de España, durante la Guerra Civil, por orden de fecha 3 de febrero de 1937, en la que se dictamina que la razón es "en atención a las circunstancias excepcionales por las que atraviesa el pais". Una vez finalizada la contienda, continúa la prohibición durante años persiguiéndose y encarcelando a quien celebraba esta fiesta con máscara.
El carnaval ha experimentado en Alhama de Granada, en los últimos años de democracia en el país, un enorme impulso desde el sector público y privado. De igual forma, desde el Ayuntamiento de Alhama se favorece y premia la participación de los alhameños en la fiesta en un intento de conservación de la singularidad de esta celebración en el municipio. Con todo ello, unido a las actividades relacionadas que han sido promovidas desde los centros educativos, el Centro de Educación de Adultos de Alhama, diferentes medios de comunicación, Asociación de Amigos del Carnaval y la labor realizada por algunos profesionales e investigadores, se ha conseguido revitalizar y mantener una tradición que fue y sigue siendo un referente de la identidad social y cultural del municipio.

Además de ser un elemento cultural importantísimo a nivel identitario, como en otros municipios andaluces, este carnaval se está reactivando por parte del Ayuntamiento convirtiéndose, para el mismo, en un factor económico como recurso de atracción turística. En este sentido, cabe señalar que debido al nivel de participación alcanzado, que traspasa el ámbito comarcal, ha sido declarado desde la administración autonómica como Fiesta de Interés Turistico de Andalucía, en función de varios criterios: "contribuye de forma destacada al desarrollo de los valores propios y de tradición popular de Andalucia, favoreciendo el mejor conocimiento de los recursos turisticos de Andalucia y el fomento, desarrollo y difusión del turismo, cumpliendo con todos los requisitos exigidos de repercusión turística, antigüedad, arraigo, valor cultural y equipamientos adecuados y necesarios".

Los alhameños comienzan el carnaval en la mañana del domingo, cuando en la carpa, situada en el Paseo del Cisne, en cuyas inmediaciones se haya el castillo, antigua fortaleza árabe, la persona designada por la Concejalía del Carnaval del Ayuntamiento de Alhama de Granada pronuncia el pregón.

Por las calles que desembocan en la Plaza de la Constitución, conocida popularmente como "la Placeta", centro neurálgico de la localidad, van apareciendo a media mañana las diferentes máscaras, 
Como en otros municipios andaluces, este carnaval se está reactivando por parte del Ayuntamiento convirtiéndose en un factor económico como recurso de atracción turística

mascarones, murgas y comparsas, que ponen el color con sus disfraces y calor con el lequillo o sonsonete de las coplas carnavalescas.

Desde los restaurantes situados en esta plaza, los bares efimeros y puestos de feriantes instalados para la ocasión, grupos de familiares y amigos presencian "un espectáculo del que igualmente, son protagonistas, porque el Carnaval ignora la distinción entre actores y espectadores en una comunicación o interacción que se produce constante entre ellos" (BAJTIN, 1971).

Para comprender las singularidades y peculiaridades del Carnaval de Alhama de Granada, hay que acercarse a los personajes, máscaras y mascarones que interactúan en el espacio de la fiesta. Por medio del disfraz se consigue justo lo que se pretende: vaciar al sujeto de su individualidad y generar una nueva personalidad que resulte anónima. De nuevo, es obligado citar a Bajtin, cuando expresa en su obra Carnaval y Literatura. Sobre la Teoría de la Novela y la Cultura de la Risa (1971) "que la máscara, como la risa, se relaciona con la transición, la metamorfosis, la violación de los límites naturales, la burla y los apodos familiares; la máscara señala la pérdida de la individualidad y la presunción de anonimato y, por consiguiente, la presunción de múltiples identidades. La máscara es la encarnación del movimiento y el cambio".

Las máscaras en el Carnaval de Alhama tienen como intención, desde la nueva identidad que expresa su vestimenta y el juego del equívoco, generar una situación o broma que provoca el desconcierto en la persona objeto de la burla. Esta absurda situación termina con una frase de la máscara que la protagoniza, pronunciada con voz chillona: "la de veces que hemos estado juntos, y no me conoces jay, qué torpe eres!".

En este sentido, Julio Caro Baroja, en su obra El Carnaval (2006), afirma que "el tiempo de Carnaval está cargado de intenciones no solamente sociales, sino también psicológicas. El hecho de poder enmascararse le ha permitido al ser humano cambiar de carácter o de identidad de género".

Por el contrario, el mascarón representa un sujeto del que los niños se asustan, de apariencia tosca, bronca y abyecta. Es un personaje irrespetuoso que en la fiesta pone de manifiesto ciertas actitudes trasgresoras. Dice el mascarón: "Me tapo la cara y te cojo el culo, porque el resto del año no te saludo". La palabra mascarón, aumentativo de la palabra máscara, se define por el Real Diccionario de la Lengua Española como "cara disforme o fantástica que se usa como adorno en ciertas obras de arquitectura".
Ambos tipos, máscara y mascarón, llevan la cara cubierta por un trapo blanco que abarca la cabeza, y se visten con ropas que ocultan totalmente su cuerpo. Sin embargo, en el caso de la máscara, el paño que cubre la cara suele estar decorado o pintado imitando un rostro cuyas expresiones son agradables y coloristas; del mismo modo, el disfraz se compone normalmente con ropas antiguas encontradas en las casas de madres y abuelas, o bien es un disfraz confeccionado para la ocasión, pero que "representa" un determinado personaje. Las máscaras suelen representar personajes invertidos sexualmente, masculinos o femeninos respectivamente. La mayor carga burlesca no radica en su vestimenta sino que, al igual que en el mascarón, es la manifestación conductual lo que aporta fuerza al personaje. Son las máscaras las que más propician las relaciones personales dentro del carnaval, en el sentido que su concepción y preparación suele hacerse en grupos de amistad o familiares. Intercambiar ropas se hace divertido y posteriormente lo será intercambiar las propias identidades. La risa proviene del engaño, de la burla en el anonimato, conseguir el equívoco en otra persona es el triunfo del carnaval. Para ello intercambian información sobre la persona a la que quieren burlar incluso a través de terceras personas que actúan como intermediarios entre burlador y burlado, de tal forma que éste no pueda reconocer la identidad de la máscara que le increpa. La burla no se revela nunca y pasado el tiempo de carnaval se olvida. Esta forma de relacionarse produce, al mismo tiempo, unión en el grupo a través de una maraña de encuentros y desencuentros en las que todos son protagonistas.

Por el contrario, el mascarón es un personaje que camina solo, en algunos casos con ropa de mujer. Nadie en principio sabe quién es y, a diferencia del posible falsete de la voz de la máscara, éste no habla, sino que emite sonidos hoscos y amenazadores. Esta figura carnavalesca suele ser un hombre aunque nada impide que una mujer se oculte tras el disfraz. Se caracteriza precisamente por su expresión hostil, puede realizar movimientos bruscos que incomoden al viandante y su actitud social va empeorándose a medida que pasan las horas y aumenta la ingesta de alcohol. Según afirmación del profesor Manuel Marín, catedrático del Departamento de Psicología Social de la Facultad de Psicología de la Universidad de Sevilla, "el mascarón es un personaje que expresa represiones acumuladas que se liberan en la fiesta debajo del disfraz".

Otro destacado elemento significativo del Carnaval de Alhama son las picaras coplas que cantan las murgas y comparsas. En comparación con otras coplas de carnaval, las de Alhama se pueden considerar "pobres", musicalmente hablando, ya que la melodía es más simple y los instrumentos más limitados. Originariamente, la murga estaba compuesta por un grupo de personas, todas ellas disfrazadas, que no se tapan la cara, para acompañar el ritmo de las copli-

\footnotetext{
1. Máscaras.

2. Grupo de máscaras con animales disfrazados.

3. Disfraces.

4 y 5 . Mascarones.

6 y 7 . Máscaras.

8. Comparsa El Pitorreo

Fotos: M. $\stackrel{a}{ }$ del Rosario Ortiz Amores
} 


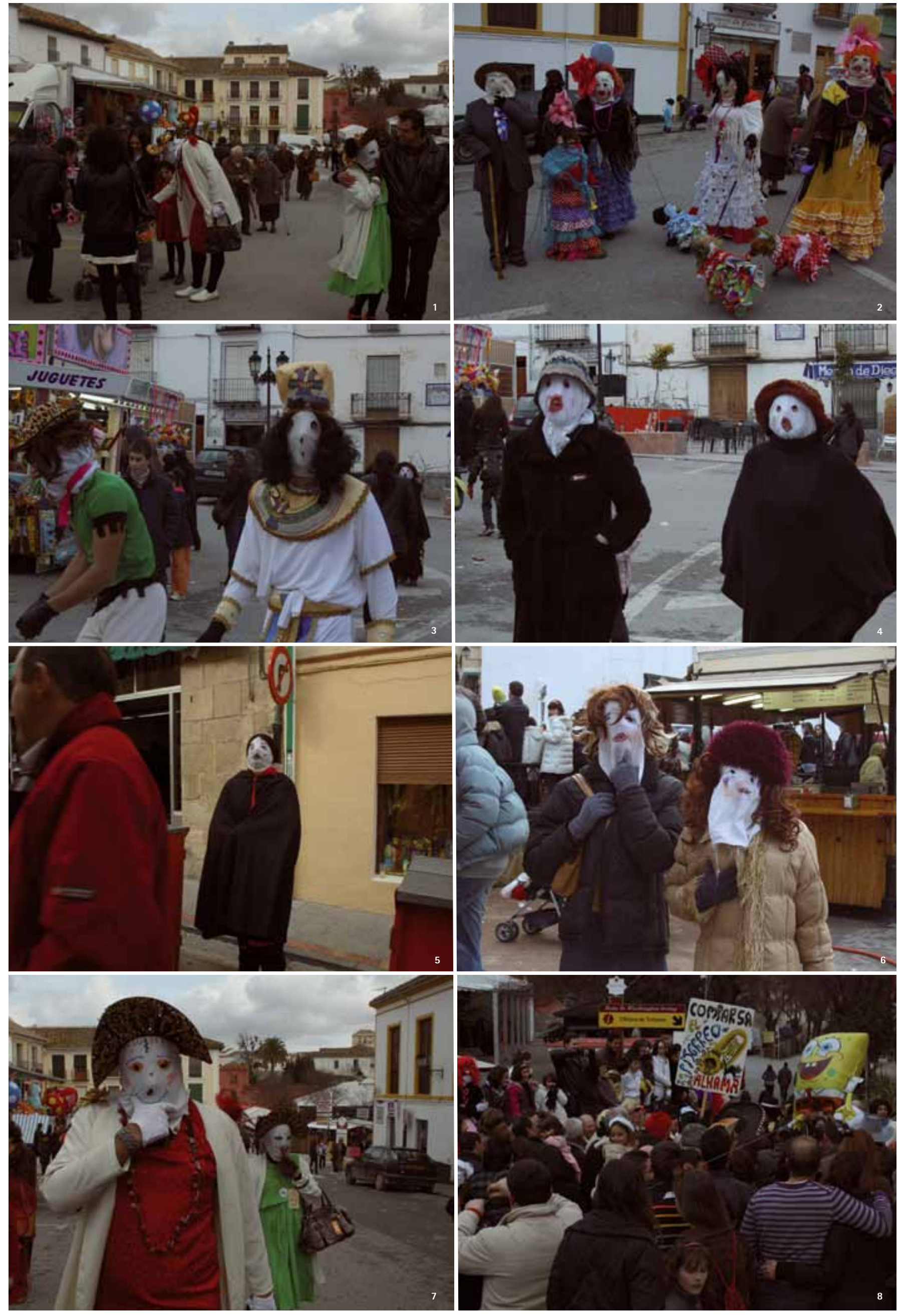




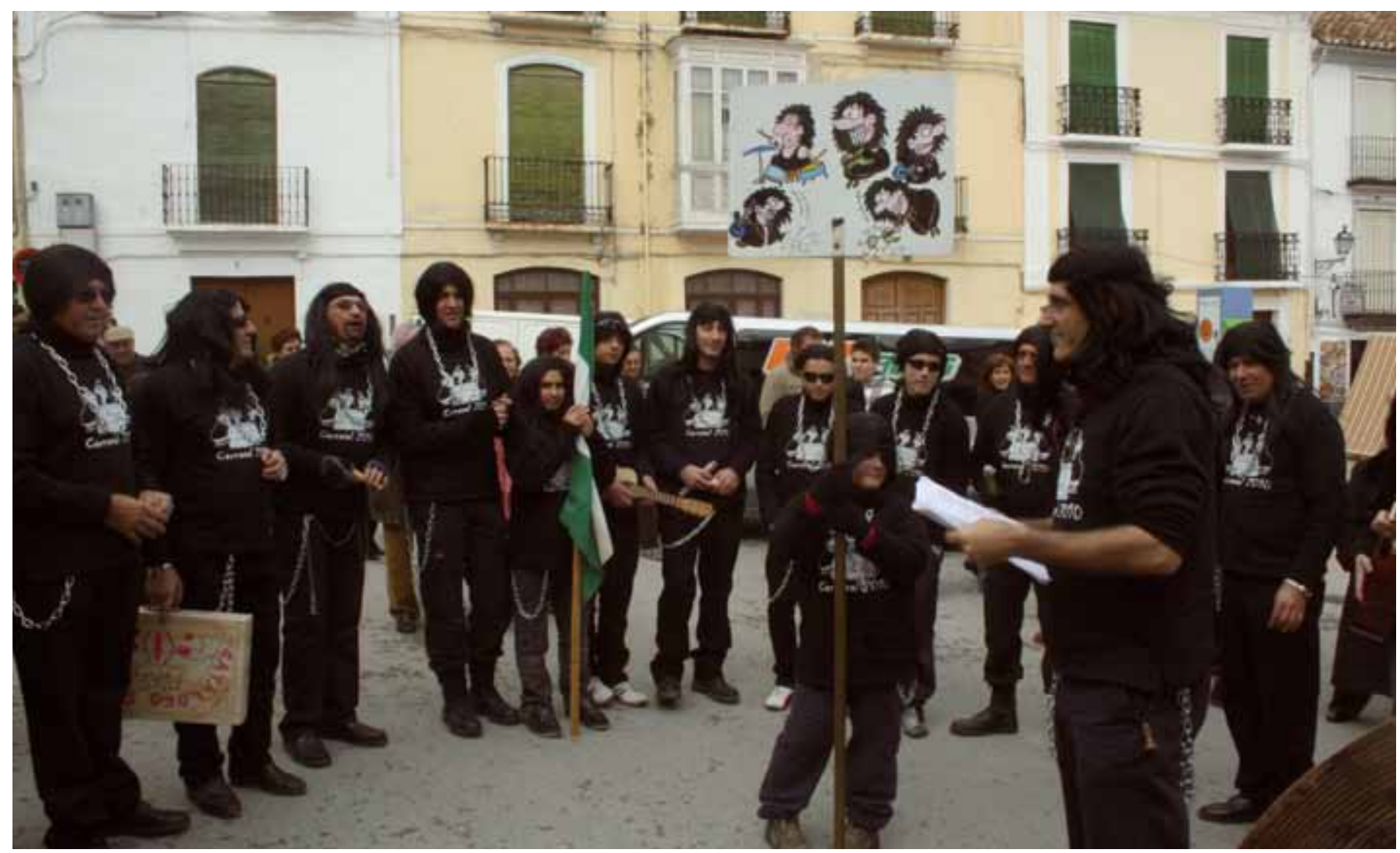

Murga La Cueva. Foto: M. $\stackrel{a}{ }$ del Rosario Ortiz Amores

llas con pitos de caña o cajas que utilizaban como instrumento de percusión a modo de tambor. Estas carencias eran debidas a la falta de formación musical de sus miembros y a los escasos recursos con los que se contaba. Por el contrario, las comparsas utilizaban otros instrumentos musicales como trompetas, tambores, violines, etc.

En el libro ya mencionado, Memoria Viva del Carnaval de Alhama de Granada,(1917-1979), editado por el Ayuntamiento de Alhama de Granada y coordinado por Antonio Arenas Maestre, destacado alhameño, maestro y colaborador en distintos medios de comunicación, y por el Centro de Educación de Adultos de Alhama y la Concejalia del Carnaval, que además contó con la colaboración de Alhama Comunicación y el Centro de Día de Alhama, quedó recogida una representación de las coplas del carnaval compuestas antes de 1980. Algunas de las letras de estas coplas eran crónicas de los sucesos locales acaecidos durante el año, como es el caso de En la casa del Ayuntamiento, escrita en torno a 1926-1927:

En la casa Ayuntamiento

papeletas repartian

para ir por el aceite

cada cual donde quería...

0 la titulada $A$ los obreros del pueblo, de contenido con censura politico-social:

...Ese es el procedimiento

de todo aquel que gobierna

amparar a quien no debe

y llenar bien su talega.
Con este trabajo se recuperaron las letras de las viejas coplas de carnaval, que se habian transmitido por tradición oral, extraídas de la memoria de los veteranos murguistas, algunos de ellos hoy desaparecidos. Con su interés por la conservación de las tradiciones del pueblo contribuyeron a esclarecer una época histórica carente de referencias documentales sobre los carnavales. La aportación fue primordial ya que sirvieron, además de para rescatar las coplillas carnavaleras, para dar a conocer la idiosincrasia de los carnavales de Alhama y hechos acontecidos que marcaron a varias generaciones.

En la actualidad, murgas como La Cueva, agrupación que se constituye en Alhama en el año 1980 y que todavía utiliza para acompañar las letras el "pito de caña", o más reciente la comparsa $E l$ Pitorreo, han colaborado también en la recuperación de numerosas composiciones.

Finalmente, el carnaval concluye con el "Domingo de Piñata", primer domingo de Cuaresma, con las actuaciones en el Paseo del Cisne de todas las murgas y comparsas, tanto locales como de otros municipios de la comarca, que se han inscrito en el registro del Ayuntamiento. Este año, entre otras, Los Cocineros del Hogar, Los Rumberos del Mediterráneo, ambas de Alhama, Grupo Nuevo Mundo, de la localidad de Huétor Tájar, Los Panzis y los Guiris, de Santa Cruz del Comercio, El Templo de los Tutankabrones, de Padul, y La Corría, de la localidad de Granada. De esta forma se pone fin, pues, a la fiesta, "a un periodo o unos periodos de aparentes desequilibrios, en los que la sociedad se lanza primero a un extremo y luego al extremo contrario" (BAROJA, 2006: 32). 
En su origen, la fiesta del carnaval se conforma como un ritual de rebelión contra la ley, contra el poder político y eclesiástico; es decir, contra los poderes establecidos. Un instrumento de equilibrio social entre dos manifestaciones ritualizadas, como son el Carnaval y la Cuaresma, de contenidos y expresiones extremadamente opuestos. Como crónica de los hechos más relevantes y la denuncia de los abusos de poder y de las desigualdades estructurales económicas y sociales.

En los últimos años, el Carnaval en Alhama de Granada ha experimentado como en otras localidades de Andalucía una pérdida de sentido o funcionalidad. Una sociedad supuestamente más igualitaria en cuanto a recursos económicos, cada vez más laica, con avances importantes en el reconocimiento de la elección de la identidad e igualdad de género, ha vaciado de contenido crítico algunas de las expresiones carnavalescas. Sin embargo, en su lugar, han surgido nuevos referentes; algunos de ellos, se puede afirmar, han sido consecuencia del proceso de globalización y, según Manuel Castells (2000), "...de la nueva sociedad que ha surgido como resultado de la revolución tecnológica y el desarroIlo de Internet", que en las tres últimas décadas del siglo $X X$, ha proporcionado y abierto una nueva ventana al mundo. Es indicativo señalar cómo algunos disfraces son de personajes populares, reales o de ficción, que traspasan el ámbito nacional y que están inspirados en la TV o en el cine de Hollywood. Además, el contenido de las coplas que interpretan las murgas y comparsas relata sucesos que tienen lugar en otros paises o van dirigida a políticos como el Presidente de los EEUU.

Hoy dia, el Carnaval de Alhama, dentro de un marco donde se funden tradición y modernidad, continúa siendo trasgresor, un tiempo de demandas y denuncias. Un lugar de encuentro de mayores y niños, de amigos y desconocidos, de autóctonos y foráneos. Un espacio simbólico donde se producen relaciones sociales temporales que son espontáneas y no tendrán continuidad en otros espacios o ámbitos durante el resto del año; de ahi, que su aspecto fundamental sea su carácter transitorio que permite darle sentido a la fiesta, y, por tanto, a la diversión. En opinión compartida por algunos de los vecinos de Alhama de Granada, en la mente de los alhameños siempre ha estado muy presente "el que dirán". Los días de carnaval muchos de ellos dejan de pensar y se divierten.

\section{En la web}

\section{PATRONATO DE LA ALHAMBRA Y EL GENERALIFE}

www.alhambra-patronato.es

Sitio web de este organismo adscrito a la Consejería de Cultura dedicado a la conservación, investigación y difusión de este monumento. En esta web podrá encontrar todos los recursos necesarios para conocer la Alhambra: galería de imágenes, visita virtual, videos, itinerarios alternativos, planos, recorrido por móvil, entre otros.

CENTRO DE PATRIMONIO MUNDIAL DE LA UNESCO. ALHAMBRA, GENERALIFE Y ALBAYZIN whc.unesco.org/en/list/314

Espacio dedicado al patrimonio mundial dentro del portal web de la UNESCO. Acceso a la ficha de declaración de la Alhambra, Generalife y Albayzin donde se exponen los criterios por los que fueron declarados bienes patrimonio mundial.

ALFANEVADA. ASOCIACIÓN PARA EL DESARROLLO RURAL DEL ARCO NORESTE DE LA VEGA DE GRANADA

www.alfanevada.info

Sitio web de esta asociación dedicada a promover el desarrollo integral de los municipios que componen actualmente el arco noreste de la vega de Granada.
Ofrece una ficha informativa de cada municipio con datos sobre su población, historia y patrimonio cultural, asi como imágenes.

\section{BIBLIOTECA DE ANDALUCÍA}

www.juntadeandalucia.es/cultura/ba

La web de esta institución ofrece el acceso a catálogos como el Catálogo de la Red de Bibliotecas Públicas de Andalucía o el Catálogo Colectivo del Patrimonio Bibliográfico Andaluz. A través de servicio la Biblioteca Responde podrá hacer una petición de información sobre temas andaluces. Entre sus recursos está el acceso a fuentes de información sobre Andalucia que contiene las obras de referencia y consultas sobre temática andaluza que se han publicado desde el inicio de la imprenta.

\section{MUSEO ARQUEOLÓGICO Y} ETNOLÓGICO DE GRANADA

www.juntadeandalucia.es/cultura/ museos/MAEGR

Portal de Museos y Conjuntos Arqueológicos y Monumentales de la Consejería de Cultura de Andalucía. Información general, historia del museo, colecciones, publicaciones, actividades y exposiciones son algunos de los recursos a los cuales podrá acceder en este espacio.

\section{CENTRO DE DOCUMENTACIÓN} MUSICAL DE ANDALUCÍA

www.juntadeandalucia.es/cultura/ centrodocumentacionmusical

Entre los recursos disponibles en el sitio web de este organismo se encuentra la Base de datos de entidades dedicadas a la investigación, documentación y enseñanza y la Base de datos de profesionales vinculados al mundo de la música y la danza. Junto a estos recursos podrá localizar las noticias aparecidas en prensa sobre música y danza así como disponer de un espacio dedicado a la música tradicional.

\section{AYUNTAMIENTO DE VÍZNAR}

www.ayuntamientodeviznar.com/ aynadamar.php

La acequia de Aynadamar en su recorrido pasa por el municipio de Viznar hasta llegar al Albaicín. El sitio web del Ayuntamiento de Viznar ofrece información histórica sobre la acequia de Aynadamar así como datos sobre su estado actual.

\section{AYUNTAMIENTO DE ALCAUCÍN \\ wwwalcaucines}

En la sección Turismo/monumentos de este sitio web podrá encontrar información sobre la cueva del Boquete de Zafarraya.

\section{AYUNTAMIENTO DE ALHAMA \\ www.alhama.org}

Sitio web de este organismo que permite conocer la historia de Alhama desde la Prehistoria hasta la Edad Contemporánea. Vistas en $360^{\circ}$ del municipio plano interactivo de la localidad y galería de imágenes son otros recursos a los que se puede acceder en esta web.

\section{MURGA LA CUEVA \\ www.murgalacueva.es}

Web de una de las agrupaciones más señeras del Carnaval de Alhama de Granada que intenta mantener las peculiaridades de un carnaval singular. Entre la información que ofrece esta web se encuentra la historia de la murga, a través de la cual se puede conocer la propia historia del municipio, así como el acceso a un histórico de coplas e imágenes.

\section{ALHAMA COMUNICACIÓN wwwalhama.com}

Medio de comunicación digital sobre Alhama y su comarca. Noticias sobre su patrimonio cultural entre otras, agenda de eventos de la localidad, herramientas sociales como foros sobre diferentes temas y posibilidad de comunicarse con el medio a través de un chat son algunos de los recursos disponibles. 